\title{
Antagonismos entre planejamento e políticas públicas, a partir da justaposição de regionalizações: o caso do estado do Rio Grande do Sul/Brasil
}

\section{Antagonisms between planning and public policy, from the regionalization juxtaposition: the state 's case Rio Grande do Sul/Brazil}

Mariana Barbosa de Souza - Doutoranda, mestra em Desenvolvimento Regional, bacharela em Direito, todos pela Universidade de Santa Cruz do Sul (UNISC), acadêmica no curso de História-Licenciatura na Universidade Norte do Paraná (UNOPAR), pesquisadoramembro do OBSERVA-DR e pesquisadora-membro do GEPEUR-CNPq: Grupo de pesquisa em Estudos Urbanos e Regionais. E-mail: marisouza_10@hotmail.com.

Verenice Zanchi - Doutoranda e mestra em Desenvolvimento Regional pela Universidade de Santa Cruz do Sul (UNISC), especialista em Gestão Empresarial pela Fundação Getúlio Vargas (FGV), administradora pelo Centro Universitário UNIVATES, pesquisadora-membro do OBSERVA-DR e pesquisadora-membro do Grupo de Pesquisa “Desenvolvimento Regional”-CNPq. E-mail: verenice.zanchi@gmail.com.

\section{Resumo}

Visa trazer à discussão o conceito de regionalização, considerando a experiência brasileira e, em particular, do Rio Grande do Sul. Como mecanismo de aprofundar a discussão, a pesquisa levou em consideração que no âmbito do desenvolvimento regional, enquanto campo interdisciplinar de reflexão sobre os processos de ocupação e planejamento do território, encontram-se conceitos chave como território, região e regionalização. Assim, este artigo visa trazer à discussão os conceitos mencionados, considerando a experiência brasileira, especificamente a experiência do Rio Grande do Sul, bem como responder a seguinte questão que embasa este estudo: existem antagonismos entre planejamento e políticas públicas a partir da justaposição de regionalizações? $\mathrm{O}$ processo legislativo e administrativo do poder público brasileiro define diversos recortes regionais para viabilizar a aplicação de políticas públicas setoriais, tais como de segurança, educação, turismo, saúde entre outros.

\section{Palavras-chave}

Território. Região. Regionalização. Desenvolvimento Regional.

\begin{abstract}
This study aims to bring to the discussion the concept of regionalization, considering the Brazilian experience and in particular the Rio Grande do Sul. As a mechanism to deepen the discussion, the survey took into account that under the regional development, as an interdisciplinary field of reflection about the occupation processes and planning of the territory, are key concepts like territory, region and regionalization. Thus, this article aims to bring to the discussion the concepts mentioned, considering the Brazilian experience, particularly the experience of Rio Grande do Sul, as well as answer the question that underlies this study: there are antagonisms between public planning and policy from the juxtaposition of regionalization? The legislative and administrative process of the Brazilian government defines several regional sections to facilitate the application of sectoral public policies, such as security, education, tourism, health among others.
\end{abstract}

\section{Keywords}

Territory. Region. Regionalization. Regional Development. 


\section{INTRODUÇÃO}

O presente artigo busca traçar uma análise da discussão do conceito de regionalização, considerando a experiência brasileira e, em particular, do Rio Grande do Sul. A partir de recortes bibliográficos, alguns conceitos como o de território, região e regionalização serão explicitados de forma simples, a fim de que o conteúdo principal do trabalho seja exposto de forma clara.

Ainda, estudando-se as práticas ocorridas no Rio Grande do Sul/Brasil, bem como o arcabouço histórico destas, objetiva-se tirar conclusões acerca das regionalizações existentes no estado.

Importante mencionar, também, que a temática do desenvolvimento regional abrange diversas facetas que implicam o entendimento das dimensões sociais, políticas, econômicas e culturais, entre outras. As relações existentes entre cultura e desenvolvimento, mormente a forma como a cultura se torna um elemento importante nas estratégias de desenvolvimento, demonstra no global, uma condição de legitimação das esferas regional e local.

A questão de pesquisa (existem antagonismos entre planejamento e políticas públicas a partir da justaposição de regionalizações?), é guiada pela necessidade de compreensão do tema, bem como sua importância para o desenvolvimento regional. Há muitas propostas de estudo acerca da sobreposição das diversas regionalizações utilizadas no Rio Grande do Sul, entretanto, ainda são incipientes e com necessidade de fortalecimento. Nesse sentido, o alvitre deste artigo é descrever as regionalizações utilizadas no estado gaúcho e suas importâncias.

O objeto de estudo trata das seguintes regionalizações: Conselhos Regionais de Desenvolvimento (COREDE), Regionais Funcionais de Planejamento e Regiões de Políticas Públicas. A hipótese é que a sobreposição de regionalizações pode ser útil em alguns casos raros. Entretanto, na sua maioria acaba por atravancar o orçamento estadual, bem como confundir a população, visto que as regionalizações se diferem umas das outras, bem como suas sedes, além de prejudicarem articulações.

A justificativa de estudar as regionalizações e sua sobreposição no Rio Grande do Sul é a de conhecer o tema, organização e estruturação estadual. Este estudo possui um recorte específico, porém não se esgota em si. Outras regionalizações aplicadas ao Rio Grande do Sul podem ser objeto de estudos futuros, tamanha é a importância da temática.

Por fim, o artigo está organizado em seções, incluindo esta introdução. Posteriormente apresenta-se uma seção que trabalha com conceitos afeitos à temática, tais como os de território e de regionalização. Após, há caracterização 
das regionalizações selecionadas para o presente estudo. Ainda, trabalhar-se-ão os procedimentos metodológicos para direcionamento dos objetivos, bem como sua análise. E, ao final, as considerações finais do tema proposto.

\section{TERRITÓRIO, REGIÃO E REGIONALIZAÇÃO}

Durante o século XX, o conceito de território confundia-se com o conceito de espaço, este que era definido como palco em que ocorriam as ações humanas. Na medida em que se aprofundou o conhecimento acerca do tema, evidenciou-se outro conceito.

$\mathrm{Na}$ virada dos séculos XX e XXI passou-se a conceituar território, propriamente dito, como espaço apropriado, moldado e usado. Território não é mais um palco, mas sim o próprio espaço em que ocorrem as ações humanas. Ainda, esta nova conceituação passa a importar-se com sustentabilidade e qualidade de vida, atrelada, ainda, ao conceito de desenvolvimento regional. Desta forma, percebe-se que o território pode ser considerado como espaço onde ocorrem as relações sociais, com características de cada local. Santos (1996) afirma que território usado é tanto resultado do processo histórico quanto a base material e social das novas ações humanas. Logo, território é um conjunto, no qual atores tentam resolver um problema comum em um determinado espaço.

Outrossim, Côrrea (1997) declara que o termo região oriundo do latim, que se refere à unidade político-regional interligado com governar - conotação eminentemente política. Para o autor, conceitualmente região é uma classe de área, isto é, um conjunto de área, como municípios, que apresenta grande uniformidade interna e grande diferença face a outros conjuntos.

Em torno de 1970 estabelece-se um pluralismo conceitual acerca do conceito de região entre os geógrafos. Nesta época, surge o conceito de região como uma resposta aos processos capitalistas. Trata-se de regionalização da divisão social do trabalho, do processo de acumulação capitalista, da reprodução da força de trabalho e dos processos políticos e ideológicos. Após, a região é considerada como foco de identificação, sendo definida como um conjunto específico de relações culturais entre um grupo e lugares particulares. Entretanto, a região como meio para interações sociais constitui-se no período pós-1970. Trata-se de uma visão política da região com base na ideia de que dominação e poder constituem fatores fundamentais na diferenciação de áreas (Raffestin é dos precursores deste conceito) (CORRÊEA, 1997).

Os três conceitos de região que surgiram após 1970 têm em comum o fato de estarem apoiados na ideia de persistência da diferenciação de áreas, não compartilhando a ideia de homogeneização do mundo. 
De outra banda, regionalizar o espaço geográfico é dividi-lo em regiões, levando em conta as diferenças paisagísticas e a organização social e econômica das diversas áreas. É possível regionalizar espaços geográficos grandes ou pequenos. Pode-se regionalizar um bairro, dividindo-o em áreas residenciais, industriais e comerciais. Pode-se também dividir o mundo inteiro, identificando, por exemplo, regiões desenvolvidas e subdesenvolvidas. Importante salientar que as regiões não são eternas, logo tal processo de regionalização é contínuo. Lencione (2001) afirma que não existe uma forma pré-determinada de regionalização, a priori, mas sim diversas formas de regionalização.

Milton Santos (2016) assevera que, atualmente, as divisões do espaço sugerem dois seguimentos, quais sejam: as horizontalidades e as verticalidades. As primeiras sugerem que existem seguimentos formados a partir de pontos que se agregam sem continuidade, como na definição tradicional de região. As segundas sugerem pontos no espaço que, separados uns dos outros, asseguram o funcionamento global da sociedade.

Continua o autor afirmando que as cidades são os pontos nos quais as horizontalidades e as verticalidades se interligam. A tendência atual é no sentido de uma união vertical dos lugares. A união vertical ocasiona a desordem espacial e sobrevive somente à custa de normas rígidas e, os vetores de modernização são entrópicos.

Por fim, cabe salientar que as regiões podem fortalecer-se horizontalmente, dando ênfase às suas particularidades e potencialidades e, consequentemente, mediante a criação de ações constituídas, elaborar uma base de vida que amplie a coesão do interesse civil, a serviço do interesse coletivo, do bem comum.

Importa mencionar que a ciência regional surgiu pós-Segunda Guerra Mundial, tendo uma abordagem disciplinar. A homogeneização das economias espaciais (KEYNES, 1985) torna-se prioritária nos países desenvolvidos, assim, nasce o ordenamento do território. Este ordenamento, obviamente, se dá a partir de uma lógica. A ciência regional estuda, principalmente, a interação urbana no território, com ênfase nas abordagens quantitativas.

De outra banda, a ciência regional passou a ser melhor analisada a partir de Walter Isard, o qual, em 1954, criou uma associação relacionada à ciência regional (BENKO, 1999). A evolução da noção de região no século XX fez os geógrafos, os historiadores e os sociólogos compreenderem que a região é um produto social gradualmente construído por sociedades nos respectivos espaços de vida.

É importante salientar que a descaracterização do período fordista faz com que as empresas, antes multinacionais, desdobrem-se em redes. Cada "nó" da rede 
está onde é mais produtivo. A estrutura social das novas comunidades reflete e reforça a divisão do trabalho no sistema produtivo. Estes autores afirmam que o mau funcionamento dos países periféricos é o "não alcançar" os países externos. Para tanto, seria necessário aumentar os investimentos em setores estratégicos. Vale dizer que ocorre um abandono à política dos polos de crescimento.

Ressalte-se que, para Raffestin (1993), no espaço se age e se interage. Cooperativas por fora, empresas enormes por dentro. Atualmente, existe a monopolização de pequenos setores pelas cooperativas. Para Pecqueur (2o12), a economia é baseada no próprio território. Ocorre a agregação de valor ao produto devido às características do próprio território. O texto de Pecqueur é de extrema importância para a superação do senso comum. O texto se apoia na teoria de regulamentação: século XX - fordista. Buscam-se melhores territórios para a instalação das empresas. Não existe qualquer tipo de preocupação com a horizontalidade do processo.

Assim, deve-se entender território como espaço usado, apropriado pela sociedade. Ainda, esta compreensão deve se dar com um viés de "internacionalizado" e relacionado à sensação de pertencimento que o sujeito desenvolve, visto que não e pode ignorar que persiste uma perspectiva diacrônica, ou seja, há a sobreposição de diferentes tempos no mesmo espaço (SANTOS, 1996).

Dallabrida (2012, p. 45) assevera que

Associada ao território, tem-se a expressão territorialidade que, para o autor, pode vir a ser encarada tanto como o que se encontra no território, estando sujeito à sua gestão, como, ao mesmo tempo, o processo subjetivo de conscientização da população de fazer parte de um território, de integrar-se a um Estado. A formação de um território dá às pessoas que nele habitam a consciência de sua participação, provocando o sentido da territorialidade que, de forma subjetiva, cria uma consciência de confraternização entre elas.

Por fim, para Pecqueur (2012), não se pode mais tratar de espaço, no sentido de território, sem estar este atrelado à economia. Assim como não se pode mais tratar da economia somente com abstrações (números). O desenvolvimento se faz onde se encontram os agentes e não em um espaço abstrato. Entendemos que os conceitos de espaço e de território são independentes, porém complementares. Assim, no mesmo sentido de Santos (1996), compreendemos que o território é formado diante de uma relação entre espaço e tempo, ou seja, a partir da apropriação de um espaço, em um específico tempo, a sociedade pratica a territorialização. 


\section{REALIDADE SOCIOECONOMICA DO RIO GRANDE DO SUL}

Para analisarmos as condições que possibilitam haver no estado do Rio Grande do Sul uma gama de regionalizações que consequentemente resultam numa disparidade entre as ações de planejamento e as de intervenção, conceber alguns aspectos históricos e econômicos é necessário. Muitas das diferenças estruturais do estado são resultados de políticas de migração e ocupação do mesmo. Políticas estas que inferiram condições econômicas distintas no território sul-rio-grandense.

$\mathrm{Na}$ compreensão e investigação de diferentes problemáticas do Rio Grande do Sul seguidamente se divide em três o seu território como fazem Magnoli, Oliveira e Menegotto (2001): a região Nordeste, a qual tem um bom índice de desenvolvimento, e as regiões Norte e Sul, que desde a década de 1990, apresentam índices decrescentes ou estagnados em nível socioeconômico.

A partir deste momento, cresce significativamente o interesse pelo regional, pois as duas últimas regiões consideravam-se longe do centro das decisões e, por conseguinte, esquecidas. Nesse contexto, inicia-se o processo de implantação dos Conselhos Regionais de Desenvolvimento (COREDE), os quais têm como principal objetivo inicial descentralizar as decisões políticas do governo na questão do planejamento, porém, este esforço resta frustrado à medida que não foi delegado o empenho necessário para alcançá-lo. As diferenças que dão suporte à regionalização do Rio Grande do Sul em Norte, Sul e Nordeste são, em parte, oriundas da história do Estado que teve diferentes políticas de ocupação e colonização.

As primeiras incursões europeias ${ }^{1}$ no Brasil Meridional, segundo Magnoli, Oliveira e Menegotto (2001), foram realizadas pelos padres espanhóis jesuítas em 1634 com a finalidade de introduzir os índios ao catolicismo, ensinar-lhes técnicas de plantio, criação de gado - sendo este os primeiros rebanhos bovinos no estado - e também a ler e escrever. Localizados nas proximidades dos rios Piratini e Jacuí, os grupos indígenas que estavam organizados em pequenas reduções jesuíticas começaram a sofrer constantes ataques de bandeirantes que visavam a obtenção da mão-de-obra indígena para trabalhar no sudeste do país.

Do ponto de vista português, o povoamento oficial do Rio Grande do Sul ocorreu, de acordo com Bernardes (1997), um século mais tarde. Em 1737, foi fundado o Forte Jesus, Maria, José no estuário da Laguna dos Patos, criando-

Anteriormente à ocupação europeia, milhares de indígenas habitavam o território do atual Rio Grande do Sul, sendo estes o motivo para as primeiras tentativas de ocupação do espaço meridional do Brasil. 
se também a Vila do Rio Grande de São Pedro, que é o atual município de Rio Grande. Devido às condições desfavoráveis para o atracamento de embarcações no litoral que se estendia de Laguna a Rio Grande e a necessidade da utilização do transporte terrestre, o Forte Jesus, Maria, José tinha grande importância militar para a Coroa Portuguesa, pois marcava o entroncamento entre o município de Laguna $^{2}$ e a Colônia do Sacramento, esta última, alvo de disputa entre Portugal e Espanha por um longo período.

Para a ocupação das áreas devolutas que se tornavam um problema militar para a Coroa Portuguesa, passou-se a ceder sesmarias a militares e civis na tentativa de proteção territorial a partir de sua ocupação. De acordo com a determinação da Coroa, era concedida uma sesmaria - que corresponde à uma área de três léguas ou 13.068 ha - para cada indivíduo. Entretanto, de acordo com Bernardes (1997) e Zarth (1997), era comum haver proprietários com três, quatro sesmarias chegando haver proprietários que possuíam dezesseis, vinte sesmarias ${ }^{3}$ - áreas de aproximadamente 260.000 ha.

Parafraseando Heidrich (2000), a porção sul do Estado apresenta predomínio estancieiro, latifúndios por extensão, característica básica das propriedades que produzem atualmente com vinculação ao agronegócio. Já no norte/nordeste há marcante presença de pequenas propriedades, elemento fundamental para o que se denomina hoje de agricultura familiar.

A ocupação do espaço agrário do Rio Grande do Sul ocorreu, portanto, de forma antagônica. O surgimento do latifúndio do Rio Grande do Sul ocorreu, nas concepções de Zarth (2002), no início da ocupação portuguesa que, desde então, preocupava-se com a forma em que ocorria a apropriação de terras ainda no século XVIII. A utilização dessa forma de ocupação do território era uma garantia de posse das terras apesar de tornar muitos campos ociosos e um problema geopolítico.

Com a concentração da terra entre poucos donos e o parco avanço tecnológico do período, de acordo com Fortes (1978), estava muito limitada a possibilidade de resultados econômicos positivos, pois esses estabelecimentos não conseguiam saciar nem o seu abastecimento interno. Dessa forma, o governo da época viu a necessidade de outra forma de uso da terra, o minifúndio produtor de alimentos.

\footnotetext{
Laguna destaca-se como importante porto no período do Tratado de Tordesilhas, sendo que a linha imaginária que dividia o Novo Mundo entre Portugal e Espanha, cortava o Brasil justamente no município.

3 As pequenas propriedades também estavam presentes neste período histórico da formação do Rio Grande do Sul, contudo, era ínfima a sua participação tanto em número de estabelecimentos quanto em área.
} 
Nesse sentido, Bernardes (1997, p. 67) afirma essa necessidade auferida pelo governo central "cogitava-se contrapor ao latifúndio escravocrata uma forma de exploração agrária refletindo o tipo europeu da pequena propriedade familiar. Nada mais seria que a continuação da experiência açoriana”.

As primeiras tentativas de implantar a pequena propriedade no Rio Grande do Sul, portanto, ocorreram no século XVIII com os portugueses oriundos do arquipélago dos Açores, e segundo Vieira (1993), estabeleceram-se no litoral e no sul do estado, empregando o sistema policultor com baixo nível tecnológico.

Entretanto, os principais implantadores do sistema de pequenas propriedades foram os alemães e os italianos, os quais se estabeleceram em locais de acesso mais difícil, porém, em terras férteis, o que favoreceu o desenvolvimento dos minifúndios. Seguindo nas premissas de Vieira (1993, p. 74), o qual afirma que esses imigrantes foram importantes para a formação do território sul riograndense,

mesmo levando em conta as práticas iniciais açoritas de estabelecimentos de chácaras policultoras, nada se assemelhava à colonização teuto-italiana em terras rio-grandenses. [...] Os colonos alemães e italianos seguiram os pressupostos da atividade agrícola da Europa, baseada na pequena propriedade, em difíceis condições de sobrevivência.

O período que está se relatando, da chegada dos imigrantes alemães e italianos ao estado para produção em pequenas propriedades, de acordo com Brum (1985), é datado de 1824, com a vinda de alemães que povoaram, inicialmente, as margens dos rios que formam o Guaíba. A partir de 1875, predominantemente imigrantes italianos migraram para o Rio Grande do Sul, ocupando terras devolutas da região Centro-Nordeste.

Nestas perspectivas de ocupação, em 1824 foi fundada a poucos quilômetros ao norte de Porto Alegre ${ }^{4}$ a Colônia de São Leopoldo. Constituída por alemães que receberam, ao menos a primeira leva de imigrantes, áreas de 160.000 braços quadrados, ou 77,44 ha - aproximadamente 170 vezes menor que as sesmarias cedidas aos portugueses -, divididos em área de campo, terra para lavoura e mata virgem, como afirma Bernardes (1997).

Estes pequenos lotes de terras cedidos a colonos alemães estavam localizados em áreas não propícias para a pecuária extensiva. Desta maneira, os colonos localizaram-se especialmente na zona das matas no nordeste do Estado, longe dos locais com a influência estancieira. Vieira (1993) realiza um recorte físico

\footnotetext{
Razão esta que, segundo Bernardes (1997), garantiu o desenvolvimento de São Leopoldo. Outras duas colônias fundadas em 1825, São João das Missões, e 1826, Três Forquilhas, fracassaram devido à distância do centro consumidor e distribuidor do estado, Porto Alegre.
} 
da localização dos alemães no estado. Segundo o autor, os colonos foram fixados no rebordo da serra geral, local onde há presença de uma densa cobertura vegetal e um rico sistema hídrico que facilitou o deslocamento e o escoamento da produção.

Em 1875, outra corrente migratória, que tinha objetivos próximos aos dos colonos alemães, as primeiras levas de imigrantes oriundos da Itália fundaram a colônia que seria o centro da colonização italiana, onde hoje se encontra o município de Caxias do Sul. Bernardes (1997) afirma que as colônias italianas no Rio Grande do Sul estavam localizadas principalmente no Planalto, em áreas com altitude que variam de 600 a 800 metros.

Desta origem histórica uma conjuntura socioeconômica no Rio Grande do Sul pode ser tecida. O sul do Estado, centro econômico até o inicio do século XX, vem constantemente perdendo importância econômica frente às demais regiões, especialmente pela precarização da produção pecuarista e baixo índice tecnológico que resultam uma baixa produtividade. Entretanto há ações pontuais alicerçadas em tecnologias de ponta que alcançam ótimos indicadores de produtividade e retorno de capital.

Em contrapartida a região nordeste do Estado, capitaneada pelo eixo Porto Alegre-Caxias do Sul, que outrora teve pouco apoio e condições estruturais e meios de produção para desenvolver suas condições socioeconômicas, atualmente centra-se como o polo econômico do Rio Grande do Sul, principalmente pela sua indústria metal mecânica e o setor terciário.

A partir das condições históricas que nortearam a distinção no território do Rio Grande do Sul, pode-se conceber as razões para haver tantas regionalizações no estado que resultam em um desafio na aplicação de políticas visto a incompatibilidade com os territórios considerados por diferentes instituições de nível estadual.

\section{SOBREPOSIÇÃO DE REGIONALIZAÇÕES NO ESTADO DO RIO GRANDE DO SUL}

Em linhas gerais definimos o RS com duas regionalizações conflitantes coordenadas por um mesmo órgão gestor, o governo do estado. Num primeiro momento temos regiões políticas e administrativas com foco na participação e formulação de que denominamos de 'Regiões de Planejamento'. Por outro lado, regiões independentes que atuam setorialmente, denominadas Regiões de Políticas Públicas. Destacamos, à incompatibilidade existente na delimitação regional da ação pública no RS. Uma vez que, delimitações territoriais dos órgãos setoriais não possuem um critério único, não possuindo, portanto áreas e abrangências similares. 
Segundo De Toni e Klarmann (2002, p. 9) as diversas regionalizações produzidas nos últimos anos são oriundas de trabalhos individuais dos órgãos setoriais do governo, os quais não são articulados entre si. Assim, cada órgão setorial possui uma delimitação regional específica. Tais delimitações não constituem regionalizações propriamente ditas, como no sentido geográfico do conceito de regionalização. Entretanto, ante a importância adquirida pelo acesso do cidadão aos serviços básicos ofertados pelo Estado, é essencial que estejam articulados, de forma operacional e, também, espacial. Do contrário, o que se tem é uma fragmentação da ação pública pelo território, ocasionando a sobreposição de programas, ineficácia da administração e aumento de custos operacionais. Ademais, há dificuldade em reconhecer os centros de referência, visto que estes mudam de acordo com a abrangência de cada órgão.

Neste sentido, podemos verificar a ausência de uma base de referência única e comum que resulta na existência de inúmeras divisões e delimitações regionais.

\section{REGIÕES DE PLANEJAMENTO}

Entendemos regiões de planejamento, como uma região derivada da aplicação de critérios políticos e administrativos instrumentalizados em atividades de planejamento, em que o território é pensado de maneira articulada com instâncias diversas não setoriais. Por considerarmos as proposições vinculadas ao desenvolvimento regional de maneira ampla e integradas, apontamos os COREDE e Regiões Funcionais como Regiões de Planejamento, diferentes das Regiões de Políticas Públicas.

\section{COREDE - CONSELHOS REGIONAIS DE DESENVOLVIMENTO}

Os COREDE são pessoas jurídicas de direito privado, organizam-se sob a forma de associações civis, sem fins lucrativos, tendo cada uma determinada abrangência territorial, conforme o Decreto-RS no 42.777/2003.

De acordo com a Constituição Estadual do RS de 1989 (Art. 149, \8), “os orçamentos anuais e a lei de diretrizes orçamentárias, compatibilizados com o plano plurianual, deverão ser regionalizados e terão, entre suas finalidades, a de reduzir as desigualdades sociais e regionais". Temos o primeiro momento da formação dos COREDE na Constituição Estadual do RS de 1989. A partir de uma iniciativa articulada do governo do Estado do RS com as respectivas regiões, os COREDE são definidos como espaços plurais e abertos de construção de 
parcerias sociais e econômicas, em nível regional. Posteriormente, os COREDE foram criados, oficialmente, pela Lei no 10.283, de 17 de outubro de 1994, na intenção de formarem fóruns de discussão e decisão a respeito de políticas e ações que visam o desenvolvimento regional.

Figura 1 - Conselhos Regionais de Desenvolvimento (COREDE) no Rio Grande do Sul

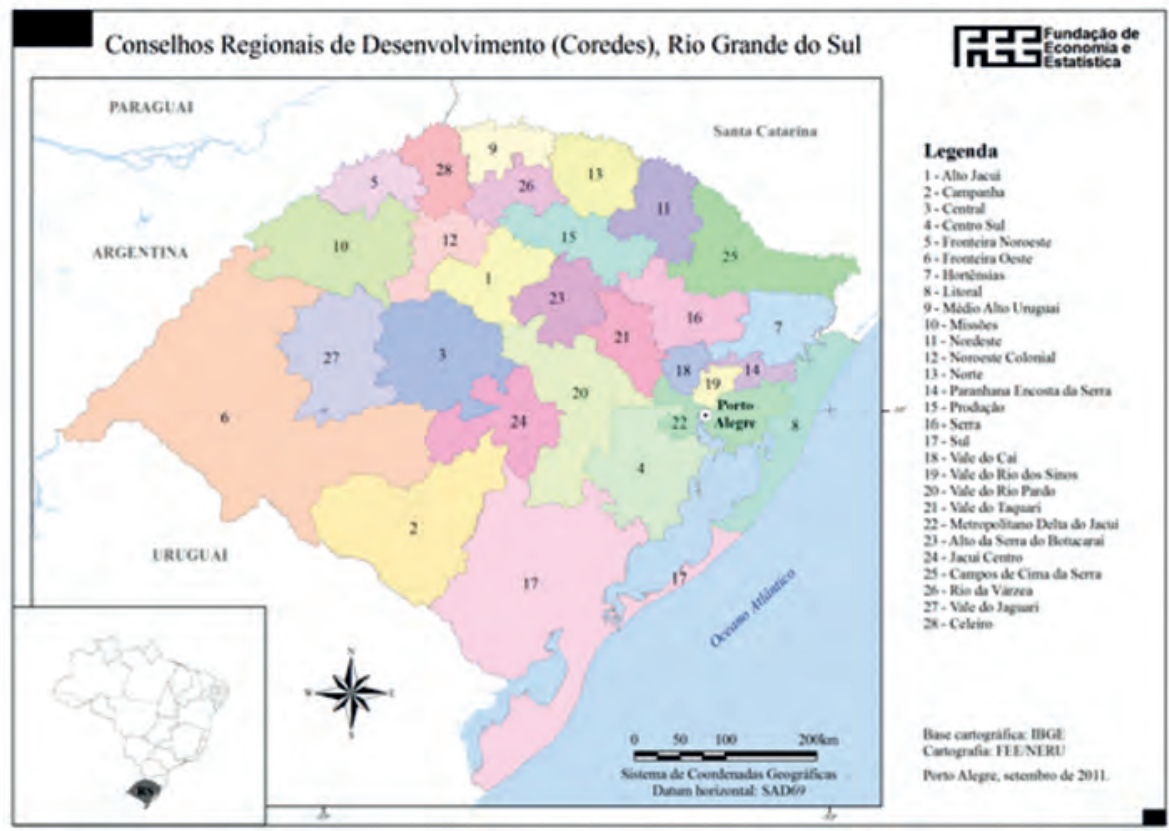

Fonte: http://www.fee.rs.gov.br/perfil-socioeconomico/coredes/detalhe/?corede=Sul

A divisão regional, inicialmente composta por 21 regiões, foi alterada em 1998, com a criação do 22ํㅡㄹ COREDE - Metropolitano Delta do Jacuí, e em 2003 com a criação dos COREDE Alto da Serra do Botucaraí e Jacuí Centro. Em 2006 foram criados as regiões Campos de Cima da Serra e Rio da Várzea. Em 10 de janeiro de 2008, por meio do Decreto n 45.436 , foram criadas as regiões do Vale do Jaguari e Celeiro e o Estado passa a contar com 28 Conselhos Regionais de Desenvolvimento (SEPLAG-RS, 2015).

A criação, a fusão e os desmembramentos obedecem a critérios como: existência de continuidade territorial; apoio de entidades políticas e instituições devidamente instaladas, ou de entidades de ensino superior, com unidades na região; existência de identidade regional, envolvendo aspectos culturais, geográficos, econômicos, sociais e de desenvolvimento; observação do número 
de municípios, população e área, entre o menor e o maior COREDE já existente; garantia que o desmembramento preserve a viabilidade dos conselhos de origem; e aprovação pelas câmaras municipais de vereadores dos municípios envolvidos. Isso torna possível aos municípios as escolhas, de qual conselho participarão.

\section{REGIÕES FUNCIONAIS}

Para fins de planejamento, os COREDE são agregados em 9 regiões funcionais. Esta agregação ocorreu por iniciativa da Secretaria da Coordenação e Planejamento do RS. Em 2006, foi elaborado um estudo, intitulado "Rumos 2015” (RIO GRANDE DO SUL, 2006), que procurou abordar temas como: ordenamento territorial, desenvolvimento regional e logística de transportes.

Figura 2 - Regiões Funcionais de Planejamento no Rio Grande do Sul

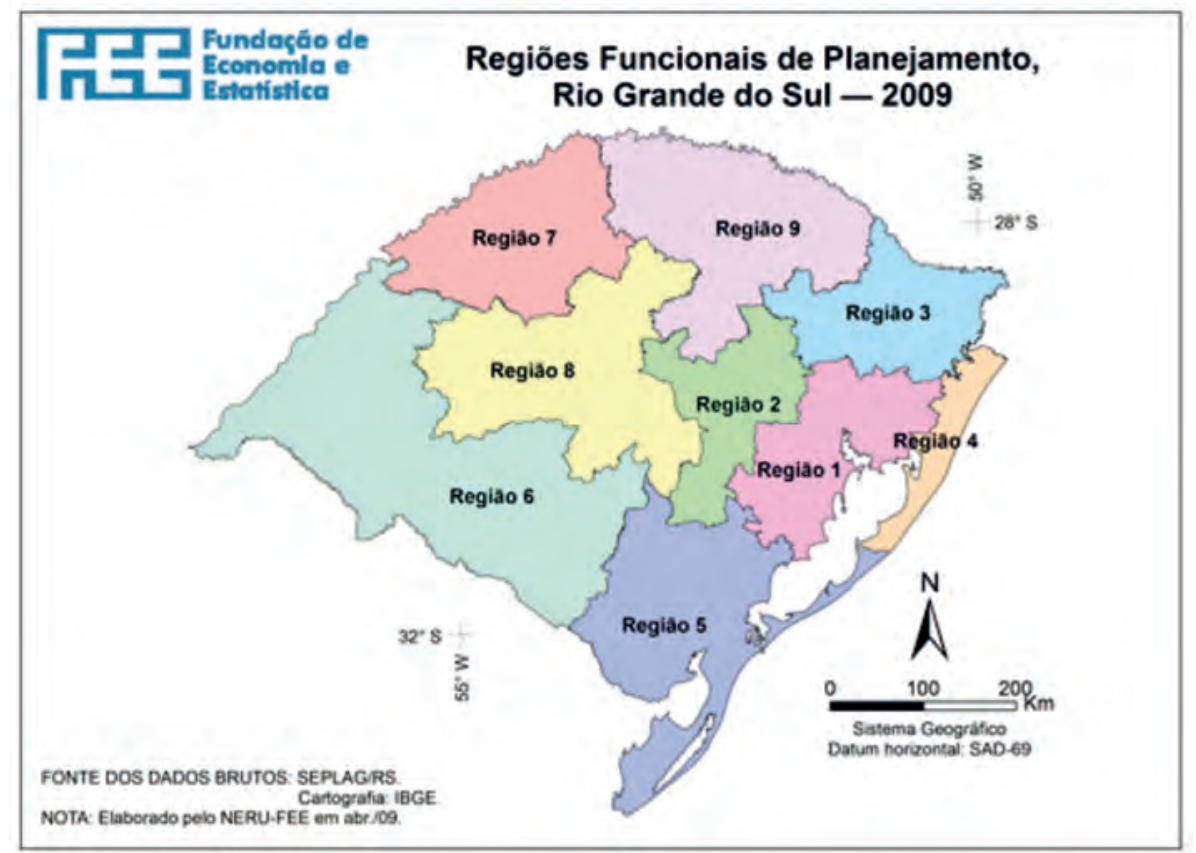

Fonte: http://www.fee.rs.gov.br/perfil-socioeconomico/coredes/detalhe/?corede=Sul

Para a definição territorial das Regiões Funcionais, foi utilizada uma matriz multicriterial. 


\section{REGIÕES DE POLÍTICAS PÚBLICAS}

As Regiões de Políticas Públicas são semelhantes às regiões de planejamento, entretanto, a compreensão do território ocorre agora a partir das necessidades de execução de determinados serviços públicos, do escopo de políticas setoriais em determinada parte do território.

Apontamos a seguir, três regionalizações diferentes, referentes a Secretarias Estaduais de Governo do RS. Fazemos alusão a regionalizações pensadas para educação, saúde e segurança.

\section{EDUCAÇÃO}

A Secretaria da Educação do RS apresenta 30 Coordenadorias Regionais de Educação (CRE) sob coordenação direta do governo do estado do RS. Estas CRE representam a secretaria estadual, na área de sua jurisdição.

De acordo com a Secretaria da Educação do RS, as atribuições das CRE são coordenar, orientar e supervisionar escolas oferecendo suporte administrativo e pedagógico para a viabilização das políticas da Secretaria. Também atuam na gestão de recursos financeiros e de infraestrutura. Assim, cada coordenadoria é responsável pelas políticas relacionadas às suas regiões.

Figura 3 - Regionalização da Educação no Rio Grande do Sul

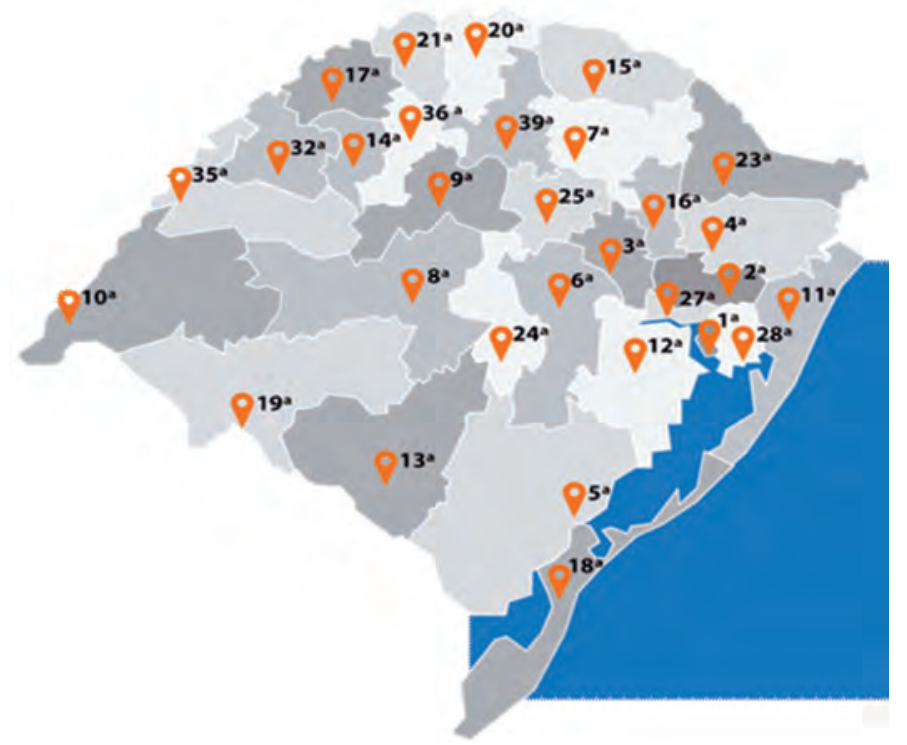

Fonte: http://www.educacao.rs.gov.br/pse/html/cre.jsp?ACAO $=$ acao1\&CRE $=0$ 
As CRE estão fortemente vinculadas a indicadores dos estabelecimentos de ensino e número de matrículas. A $7^{\text {a }}$ CRE (Passo Fundo) apresenta dois enclaves, resultantes de seus desdobramentos que ignoraram a continuidade territorial. São desconsideradas as regionalizações já apresentadas, mesmo com as coordenadorias tendo suas definições escusas.

\section{SAÚDE}

A Secretaria Estadual de Saúde, também é dividida em Coordenadorias Regionais. A saúde foi regionalizada em sete macrorregiões: Centro-Oeste, Metropolitana, Missioneira, Norte, Serra, Sul e Vales. E 19 microrregiões que correspondem às Coordenadorias Regionais de Saúde (CRS), que são responsáveis pelo planejamento, acompanhamento e gerenciamento das ações e serviços de saúde, em cooperação técnica, financeira e operacional com os gestores municipais e prestadores de serviços de saúde.

Cada CRS apresenta um território definido, uma sede, um coordenador, com no mínimo trinta e até cem funcionários.

Figura 4 - Regionalização da Saúde no Rio Grande do Sul

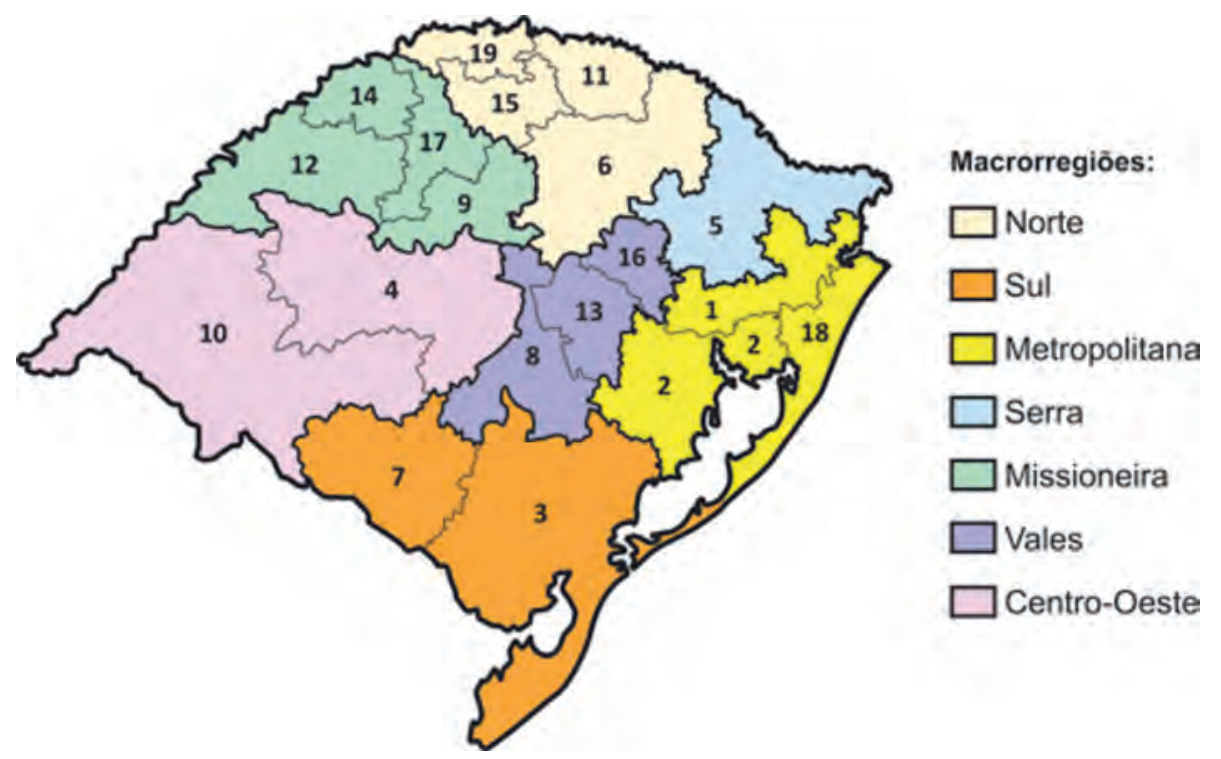

Fonte: http://www.saude.rs.gov.br/lista/104/Coordenadorias_Regionais

$\mathrm{Na}$ Região Metropolitana de Porto Alegre a $2^{\mathrm{a}}$ CRS (Porto Alegre, mesma denominação da $1^{\mathrm{a}} \mathrm{CRS}$ ) está subdividida em outras duas regiões devido ao crescimento dos municípios abrangidos. Outro exemplo de limitações na 
regionalização vigente. Para a definição das macrorregiões foram identificados hospitais de referência macrorregional, capazes de atender aos casos mais complexos. Já para as coordenadorias regionais, foram apontados hospitais de referência regional e microrregional, além de unidades locais de saúde com capacidade de transformação em pequenos hospitais, focando atendimento predominantemente ambulatorial e com internações curtas e de baixa complexidade.

\section{SEGURANÇA}

A Secretaria de Segurança Pública no RS engloba quatro órgãos: a Polícia Civil, com a atribuição constitucional de investigação criminal e dos atos de polícia judiciária; a Polícia Militar (que é chamada de Brigada Militar no RS), encarregada constitucionalmente do policiamento preventivo ostensivo; a Superintendência dos Serviços Penitenciários (SUSEPE), responsável pela execução administrativa das penas privativas de liberdade e das medidas de segurança; e o Instituto Geral de Perícias (IGP), responsável pelas investigações a partir de perícias médicolegais, criminalísticas e serviços de identificação. Cada um destes órgãos apresenta atribuições distintas, como pode ser verificado e devido a estas atribuições são regionalizados singularmente. Dentro de uma mesma secretaria estadual, identificamos diferentes divisões regionais o que dificulta a articulação territorial destes órgãos e o manejo de pessoal e material.

Segundo o Decreto n 42.162, de 07 de março de 2003, o RS fica dividido em 33 (trinta e três) Regiões Policiais, para efeito da organização dos órgãos e serviços da Polícia Civil, submetidas ao Departamento de Polícia Metropolitana (DPM) e ao Departamento de Polícia do Interior (DPI). Estas duas instâncias subdividem territorialmente o RS em 4 Divisões Regionais Metropolitanas (DRM) e 29 Delegacias de Polícia Regionais (DPR), respectivamente vinculadas aos departamentos mencionados acima.

A Brigada Militar, conforme Lei no 10.991, de 18 de agosto de 1997, é polícia militar do Estado do Rio Grande do Sul, trata-se de “...uma instituição permanente e regular, organizada com base na hierarquia e na disciplina, destinada à preservação da ordem pública e à incolumidade das pessoas e do patrimônio". A Brigada Militar estrutura-se em órgãos de Direção, de Apoio e de Execução. Fazem para da Brigada Militar: o Comando do Corpo de Bombeiros (CCB); e o Comando Rodoviário da Brigada Militar (CRBM). Este último, para sua atividade, possui três Batalhões Rodoviários (BRBM), localizados em Passo Fundo, Cachoeira do Sul e Bento Gonçalves, com frações rodoviárias ao 
longo das rodovias estaduais. O CCB está subdividido territorialmente em doze Comandos Regionais de Bombeiros e um Grupamento de Busca e Salvamento.

O principal órgão de execução da Brigada Militar divide-se territorialmente em 12 Comandos Regionais de Policiamento Ostensivo (CRPO), constituído por Batalhões de Polícia Militar (BPM).

A rede prisional da SUSEPE compreende unidades classificadas por fundação, albergues, penitenciárias, presídios, colônia penal e instituto penal. Organizadas por região, apresenta uma territorialidade de 10 Delegacias Penitenciárias Regionais (DPR), as casas prisionais estão distribuídas na capital e interior do Estado, acolhendo presos do regime aberto, semiaberto e fechado.

O IGP apresenta como órgãos internos, sob a coordenação da Supervisão Técnica: o Departamento de Criminalística (DC), o Departamento Médico-Legal (DML), o Departamento de Identificação (DI) e o Laboratório de Perícias (LP). A divisão territorial do IGP no que diz respeito às atividades de perícia forense apresenta 10 coordenadorias. Estas Coordenadorias foram instituídas por meio do Decreto no 47.657, de 13 de dezembro de 2010 .

Quadro 1 - Regionalizações da Segurança no Rio Grande do Sul

\begin{tabular}{|c|c|}
\hline Órgão & Regionalizaçōes \\
\hline Polícia Civil & $\begin{array}{l}4 \text { Divisōes Regionais Metropolitanas (DRM) e } 29 \\
\text { Delegacias de Policia Regionais (DPR). }\end{array}$ \\
\hline Policia Militar & $\begin{array}{l}\text { Órgãos de Direção, de Apoio e de Execução. } \\
\text { Comando do Corpo de Bombeiros (CCB); Comando } \\
\text { Rodoviário da Brigada Militar (CRBM) - três } \\
\text { Batalhōes Rodoviários (BRBM). O CCB está } \\
\text { subdividido territorialmente em doze Comandos } \\
\text { Regionais de Bombeiros e um Grupamento de Busca } \\
\text { e Salvamento. }\end{array}$ \\
\hline SUSEPE & $\begin{array}{l}\text { Fundação, albergues, penitenciárias, presídios, } \\
\text { colônia penal e instituto penal. São } 10 \text { Delegacia } \\
\text { Penitenciárias Regionais (DPR). }\end{array}$ \\
\hline IGP & $\begin{array}{l}\text { Departamento de Criminalistica (DC), } \\
\text { Departamento Médico-Legal (DML), } \\
\text { Departamento de Identificação (DI) e o Laboratório } \\
\text { de Perícias (LP). São } 10 \text { coordenadorias. }\end{array}$ \\
\hline
\end{tabular}

Fonte: elaboração própria a partir dos dados da pesquisa.

A divisão territorial e a definição da sede de cada Coordenadoria Regional de Perícia (CRP) foram definidas a partir de dois critérios principais: cidades com maiores índices de violência e com maior demanda de perícia; e área de cobertura do posto regional em um raio de atendimento de aproximadamente $150 \mathrm{~km}$.

Contudo, ressaltamos as diferentes divisões regionais dentro da mesma proposta setorial de segurança dificultando, mesmo, as relações internas deste órgão. 


\section{CONSIDERAÇÕES FINAIS}

A justaposição de regionalizações, na maior parte dos casos, gera dificuldades na mobilização e na articulação entre as diferentes áreas existentes. Após considerarmos esta problemática, o estudo buscou traçar uma análise da justaposição de regionalizações, considerando a experiência brasileira e, em particular, do Rio Grande do Sul.

As discussões propostas neste artigo confirmam que a relação das regiões de políticas públicas com as regiões de planejamento, seja apenas referente à consulta popular. Isto é, a mobilização da comunidade para angariar investimentos nas áreas de educação, saúde e segurança. Assim, constatamos que existem regionalizações sobrepostas entre regiões de políticas públicas e regiões de planejamento. Este fator mostra-se como um dificultador em mobilizar e articular estas diferentes áreas.

Lembramos ainda que os critérios em alguns decretos e leis que instauram as regionalizações citadas, são dúbios, não são claros ou ainda nem são mencionados. Ou seja, regionalizações de interesses políticos e outros motivos, e critérios não muito claros à sociedade e pesquisadores, representam o governo, suas propostas, seus métodos e, também, não deixam de revelar, sua funcionalidade, objetivos e concepções políticas e ideológicas.

Cabe ainda destacar que, atualmente, a área da saúde, em todo o país, está em fase de discussão e redefinição a de suas regionalizações, devido a existência de um Decreto Nacional que prevê regiões interestaduais e até internacionais de saúde. Há uma tendência de readaptação destas regionalizações, porém, desconsiderando outras regionalizações setoriais vigentes, permanecendo as dificuldades de articulação entre as regiões do RS.

Diante do exposto, confirma-se a hipótese inicial de que a sobreposição de regionalizações pode ser útil em alguns casos raros. Entretanto, na sua maioria acabam por atravancar o orçamento estadual, bem como confundir a população, visto que as regionalizações se diferem umas das outras, bem como suas sedes, além de dificultarem articulações.

Por fim, importa destacar que as regionalizações enfrentam diversos desafios, dentre os principais estão a superação dos limites territoriais municipais e a importância enquanto representatividade, ou seja, quanto menos representativa a região, menor atenção ela ganha.

Como sugestão para estudos futuros, torna-se importante analisar melhor a relação entre as regionalizações, bem como investigar outras regionalizações que são utilizadas pelo Governo do Rio Grande do Sul. Ainda, analisar como os atores sociais são decisivos na elaboração de determinadas regionalizações. 


\section{REFERÊNCIAS:}

BENKO, Georges. A ciência regional. Oeiras: Celta Editora, 1999.

BERNARDES, Nilo. Bases geográficas do povoamento do Estado do Rio Grande do Sul.

Ijuí-RS: UNIJUÍ, 1997.

BRASIL. Lei nº 11.445, de 05 de janeiro de 2007. Estabelece diretrizes nacionais para o saneamento básico; altera as leis $\mathrm{n}^{\circ}$ 6.766, de 19 de dezembro de 1979, 8.036, de 11 de maio de 1990, 8.666, de 21 de junho de 1993, 8.987, de 13 de fevereiro de 1995; revoga a $\mathrm{Li} \mathrm{n}^{\circ}$ 6.528, de 11 de maio de 1978; e dá outras providências. Disponível em: < http://www.planalto.gov.br/ccivil_03/_ato20072010/2007/lei/111445.htm>. Acesso em: maio 2016.

Lei $\mathrm{n}^{\circ}$ 11.107, de 06 de abril de 2005. Dispõe sobre normas gerais de contratação de consórcios públicos e dá outras providências. Diário Oficial [da] República Federativa do Brasil, Brasília, 07 de abril de 2005. Disponível em: <http://www.planalto.gov.br/ccivil_03/_ato2004 2006/2005/Lei/L11107. htm>. Acesso em: maio 2016.

Constituição 1988. Constituição da República Federativa do Brasil. Brasília, DF: Senado, 1988.

BRUM, Argemiro. Modernização da agricultura: trigo e soja. Ijuí-RS: FIDENE, 1985.

CORRÊA, Roberto Lobato. Região: A tradição Geográfica. In: CORRÊA, Roberto Lobato. Trajetórias geográficas. Rio de janeiro: Bertrand Brasil, 1997.

DALLABRIDA, Valdir Roque. Território e desenvolvimento sustentável: indicação geográfica da erva-mate de ervais nativos no Brasil. Informe Gepec, Toledo, v. 16, $\mathrm{n}^{\circ}$ 1, p. 42-59, 2012. Disponível em: < http://www.unc.br/ mestrado/docs/ARTIGO-DESENVOLVIMENTO-SUSTENTAVEL-E\%20 IG-GEPEC.pdf> Acesso em: maio 2016.

DE TONI, J.; KLARMANN, H. Regionalização e Planejamento, reflexões metodológicas e gerenciais sobre a experiência gaúcha. Ensaios FEE, Porto Alegre, v. 23, Número Especial, p. 517-538, 2002. Disponível em: <http:// revistas.fee.tche.br/index.php/ensaios/article/viewFile/2019/2400>Acesso em: maio 2016. 
EDUCAÇÃO-RS. Secretaria Estadual de Educação, 2012. Disponível em: <http://www.educacao.rs.gov.br>. Acesso em: ago. 2015.

FORTES, João Borges. Os casais açorianos: presença lusa na formação do Rio Grande do Sul. Porto Alegre: Martins Livreiro, 1978.

HEIDRICH, Álvaro Luiz. Além do latifúndio: geografia do interesse econômico gaúcho. Porto Alegre: UFRGS, 2000.

KEYNES, John. Teoria geral do emprego, do juro e da moeda. (Os economistas). São Paulo: Nova Cultura, 1985.

LENCIONE, Sandra. Região e Geografia - a noção de região no pensamento geográfico. In: CARLOS, Ana Fani. Novos Caminhos da Geografia. São Paulo: Contexto, 2001.

MAGNOLI, Demétrio; OLIVEIRA, Giovana; MENEGOTO, Ricardo. Cenário Gaúcho: Representação histórica e geográfica. São Paulo: Editora Moderna, 2001.

RAFFESTIN, Claude. Por uma Geografia do Poder. São Paulo: Ática, 1993.

RIO GRANDE DO SUL. Decreto n 47.657, de 13 de dezembro de 2010. Disponível em: <http://www.al.rs.gov.br/Legis/Arquivos/DEC\%2047.657. pdf $>$. Acesso em: maio 2016.

Rumos 2015: estudo sobre desenvolvimento regional e logística de transportes no Rio Grande do Sul. Porto Alegre: SCP, 2006. v.1.

Decreto $\mathrm{n}^{\mathrm{Q}}$ 42.162, de 07 de março de 2003. Disponível em: <http:// www.al.rs.gov.br/legis/M010/M0100099.ASP?Hid_Tipo=TEXTO\&Hid_ TodasNormas $=409 \&$ hTexto $=\&$ Hid_IDNorma $=409>$. Acesso em: maio 2016.

Decreto $\mathrm{n}^{2}$ 42.777, de 22 de dezembro de 2003. Disponível em: < http:/ / www.al.rs.gov.br/Legis/M010/M0100099.ASP?Hid_Tipo=TEXTO\&Hid_ TodasNormas $=47168 \&$ hTexto $=\& H i d \_I D N o r m a=47168>$. Acesso em: mai. 2016.

Decreto n³8.107, de22 de janeiro de 1998. Disponívelem: <http:/ www. brigadamilitar.rs.gov.br/Estrutura/Bombeiros/Legisla\%C3\%A7\%C3\%A3o/ DecEst38107-22jan1998.html>. Acesso em: maio 2016.

Lei n⿳0 10.991, de 18 de agosto de 1997. Com as alterações da Lei 11.736 de 13 de Jan 2002. Disponível em: < http:/ / www.brigadamilitar.rs.gov.br/ Estrutura/Bombeiros/Legisla\%C3\%A7\%C3\%A3o/LeiEst10991-18ago1997. html>. Acesso em: maio 2016. 
Constituição Estadual de 1989. Disponível em: < http://www.al.rs.gov. br/prop/legislacao/constituicao/constituicao.htm>. Acesso em: maio 2016.

SANTOS, Milton. A natureza do espaço - técnica e tempo, razão e emoção. São Paulo:Hucitec, 1996.

SANTOS, Milton. O papel ativo da Geografia - um manifesto. Disponível em: <www.revistaterritorio.com.br/pdf/09_7_santos.pdf> Acesso em: maio 2016.

SANTOS, Milton. Sociedad y espacio: la formación social como teoría y como método. In: De la totalidad al lugar. Barcelona: Oikos-Tau, 1996.

SAQUET, Marcos Aurélio. Proposições para Estudos Territoriais. Revista GEOgrafia, v.8, , n.15, 2006.

SAÚDE-RS. Secretaria Estadual de Saúde. Disponível em: < http://www.saude. rs.gov.br>. Acesso em: mai. 2016.

SEPLAG-RS. Secretaria de Planejamento, Gestão e Participação Cidadã. 2014. Disponível em: <http://www.seplag.rs.gov.br>. Acesso em: ago. 2015.

SIEDENBERG, D. R.; BÜTTENBENDER , P. L.; ALLEBRANDT, S. L. Conselhos Regionais de Desenvolvimento (COREDES) RS: articulações regionais, referenciais estratégicos e considerações críticas. Revista DRd Desenvolvimento Regional em debate v. 1, n. 1, dez. 2011. Disponível em: $<$ www.periodicos.unc.br/index.php/drd/article/download/66/91> Acesso em: maio 2016.

SSP-RS. Secretaria da Segurança Pública. Disponível em: <http://www.ssp. rs.gov.br>. Acesso em: maio 2016.

VIEIRA, Euripedes Falcão. Geografia econômica do Rio Grande do Sul. Porto Alegre: Sagra, 1993.

ZARTH, Paulo Afonso. Do arcaico ao moderno: o Rio Grande do Sul agrário do século XIX. Ijuí-RS: Ed.Unijuí, 2002.

História agrária do Planalto Gaúcho 1850-1920. Ijuí-RS: Ed.Unijuí, 1997. 